\title{
UN NUEVO MODELO DE FAMILIA
}

\author{
Inés Alberdi \\ (Universidad Complutense)
}

\section{INTRODUCCION}

¿Es válido hablar de familia moderna y de familia tradicional? ¿Puede esto ayudarnos a comprender la importancia de los cambios que observamos en la familia española? Sólo en función de cómo utilicemos los criterios de tradición y modernidad podemos responder a estas preguntas. Hay una serie de sociólogos que han pretendido analizar las familias actuales en comparación con los comportamientos familiares en sociedades anteriores -que unos llaman tradicionales, otros preindustriales, otros patriarcales- haciendo en general referencia a formas familiares en sociedades donde los modos de producción eran otros y donde los comportamientos familiares y, a veces también, las formas o estructura de la familia igualmente lo eran, en consonancia con esa diferente vida social.

No hay, en la utilización que vamos a hacer de los términos moderno y modernidad, ninguna connotación valorativa, en cuanto que, aun cuando asociemos a ellos alguna característica que se nos aparezca como positiva, no podemos olvidar el alto coste de pérdida de otros valores que la modernidad conlleva. En cuanto a la tradición o la vida tradicional ocurre lo mismo. No estamos en contra de lo tradicional aunque tnuy frecuentemente definamos como tradicionales conductas sobre las que tenemos prejuicios negativos como podría ser, por ejemplo, la doble moral sexual en cuanto valoración diferenciada de los comportamientos personales según el sexo, y que es una 
constante en las sociedades tradicionales europeas hasta mediados del siglo $\mathrm{xx}$.

En este trabajo se va a tratar de evaluar la posible aparición o no en España de una forma familiar moderna, partiendo para la conceptualización de dicha familia moderna de los recientes análisis de Shorter, Flandrin, Roussel y otros. Se pretende comparar estos modelos familiares con la situación española en su aspecto legal. La hipótesis de trabajo es que, mientras que a nivel de comportamientos y actitudes las formas nuevas de familia van emergiendo poco a poco en España y desde 1965 configuran los principales cambios que se dan en ella - una estructura con menor número de miembros, unas relaciones nuevas en el interior de la pareja, diferentes actitudes hacia los hijos, etc.-, a nivel legal los cambios son más tardíos y culminan con las reformas del Código Civil en 1981, donde ya se refleja un modelo nuevo de familia. Creemos que la familia española cambia profundamente a lo largo de los últimos veinte años, pero que estos cambios no se consolidan legalmente hasta muy recientemente, y que, cuando lo hacen, las normas legales superan en sus planteamientos la situación real de la evolución familiar, configurando como realidad legal un modelo de familia que, aunque existe en ciertos sectores del país no está todavía generalizado. La normativa deviene así más moderna de lo que es la familia media, no se adecúa a ésta sino a la fila de los pioneros (tomando el símil de Willmot y Young)' que se presentan como modelo a nivel de imagen simbólica de hacia donde caminamos.

Hay una aceptación generalizada entre los sociólogos de la familia sobre que la legitimidad del matrimonio actual la da el sentimiento recíproco de los esposos; cada vez se valora más un matrimonio según como satisface sus necesidades emocionales individuales. ${ }^{2}$ Creemos que este fenómeno va emergiendo en España, pero presenta dificultades en cuanto a su evaluación. Podríamos decir lo mismo con respecto a otros rasgos cualitativos de la familia actual. Por ejemplo, la creciente importancia de la relación paterno-filial que se traduce en angustia y preocupación acerca de la educación de los niños; éste es un rasgo que aparece como extensión del fenómeno de la maternidad y que, a diferencia de ésta, es compartido por el padre y por la madre: interés por la salud, la educación y la estabilidad emocional del hijo, etc. Todos estos fenómenos que definen los comportamientos fami-

1. M. Young y P. Willmot, La familia simétrica, Tecnos, Madrid, 1975. En el último capítulo «Hacia el futuro» hacen una previsión de lo que puede ser la familia en las sociedades desarrolladas, en los próximos años, pp. 237-269.

2. A. J. Cherlin, Marriage, Divorce, Remarriage, Harvard University Press, 1981. Citado en A. Hacker, Farewwel to the Family?, «The New York Review», 18 marzo 1982. 
liares, más allá de los datos concretos del tamaño, número de hijos, edad de matrimonio y de maternidad, tienen en común su enorme importancia y la dificultad de su estimación si no se llevan a cabo investigaciones muy cuantiosas. Por eso creo que, a la hora de analizar la familia, si no podemos conocer a fondo los comportamientos, sí podemos analizar las normas que los informan. Las normas que aparecen en las sociedades europeas como leyes no lo son siempre ni necesariamente, y tienen una gran influencia en la configuración de los comportamientos familiares, ya sea por su aceptación o por su trasgresión. Esta forma de analizar la realidad actual de las familias en España es la que nos va a interesar; la normativa legal que las somete. La realidad y el derecho no van unidos siempre, y también es significativo observar a nivel familiar la divergencia entre la ley y la costumbre. Hasta hace pocos años el análisis de la contradicción entre la normativa legal y la realidad social en nuestro país hacía pensar que aunque los cambios eran muy grandes y profundos en la familia española la ley no los contemplaba. Un caso muy significativo ha sido en nuestra historia reciente el del divorcio. La ruptura matrimonial era una realidad bastante extendida que, sin embargo, la ley desconocía. Una cuestión que aún hoy marca ese distanciamiento entre los valores aceptados por la sociedad y el espíritu de las leyes es la actual regulación del aborto. En amplias capas de la sociedad española hay una aceptación general de los motivos que puedan tener las mujeres para interrumpir su embarazo y un buen número de mujeres abortan, ya sea en el extranjero o clandestinamente en el interior del país; sin embargo, la ley sigue hablando el lenguaje intransigente de la moral católica de principios de siglo, que ya no es la moral social general. Cuando las leyes dan la espalda de un modo tan evidente a la realidad social, no puede mirarse sólo a los textos legales para hablar de la familia española, habrá que tener en cuenta, también, las costumbres que respetan o reconocen esa norma. Pero creemos que en la mayoría de los temas familiares se ha llevado a cabo un gran esfuerzo en los últimos años para adecuar la normativa a la realidad social y, lo que es más interesante, para definir las vías de evolución de esa realidad; esta normativa es la que vamos a analizar.

\section{DIFERENTES MODELOS FAMILIARES}

Los textos legales no definen qué es la familia. Las definiciones de familia las encontramos más frecuentemente entre los sociólogos, los antropólogos y los historiadores que pretenden señalar qué es aquello que entienden por familia. Una definición sencilla sería la de «personas unidas 
por el matrimonio o la filiación, que viven bajo el mismo techo». ${ }^{3}$ Esta definición tan general engloba a casi todas las familias posibles, pero no dice nada de la relación social fundamental que une a los miembros de la familia en nuestra sociedad, el hecho de ser una unidad económica básica. El ver la familia como una unidad económica se identificó tanto, en un principio, con que fuera una unidad de producción -cuestión esta que sólo a veces es cierta y que fue general en las familias artesanas y campesinas de tiempos pasados- que parece que al dejar de ser unidad de producción la familia ha de perder su carácter de unidad económica. Pero hay otro aspecto económico fundamental que la familia sigue manteniendo y es el ser unidad de consumo, con la importancia tan grande que esto tiene en la actualidad. Por esto podría hacerse una definición algo más extensa de la familia en la que se señalara este aspecto; la familia sería «dos o más personas unidas por el matrimonio o la filiación, que viven juntas, ponen sus recursos económicos en común y consumen conjuntamente una serie de bienes». El no determinar el número de miembros ni las relaciones entre ellos se debe a que así pueden considerarse varias familias incompletas como tales, por ejemplo el matrimonio sin hijos o la mujer o el hombre solos que viven con sus hijos. Una familia implica un hogar, pero no son términos indistintos. Los miembros de una familia tienen unas relaciones peculiares entre sí que no tiene un grupo de amigos, con $o$ sin hijos, que viven en común. (Así se diferencia en la mayoría de los autores que hablan de famille y menage en francés, y de family y bousebold en inglés.) Esta voluntad de poner los recursos económicos en común, fundamentalmente la vivienda, es lo que forma un hogar y la calificación de familia puede añadirse con la existencia de lazos de parentesco y esa voluntad niveladora que da el consumir como una unidad.

Los textos legales no definen qué es una familia, pero al establecer una serie de relaciones y obligaciones entre parientes configuran y delimitan cuál es la estructura familiar en la que están pensando. No hay conceptualización explícita de la familia, pero se dibuja una determinada familia en los textòs. Así ocurre en las leyes españolas en las que se marca privilegiadamente una estructura de familia nuclear, que es aquella formada escuetamente por el matrimonio y los hijos. El modelo de familia nuclear no puede equipararse ya al de familia moderna, pues los historiadores de la familia han demostrado la existencia generalizada de familias nucleares en siglos pasados. ${ }^{4}$ En España se privilegia la forma de la familia nuclear sobre otros

3. Es la que Flandrin presenta como definición del diccionario. J. L. Flandrin, Orígenes de la familia moderna, Ed. Crítica, Barcelona, 1979, p. 11. 1972.

4. P. Laslett, Housebold and Family in Past Time, Cambridge University Press, 
modelos de familia en tanto en cuanto el Código Civil propone la distribución igualitaria de la herencia entre todos los hijos..$^{5}$ Otras estructuras familiares han persistido en ciertos lugares del país, allí donde la transmisión de los bienes es diferente. ${ }^{6}$ Pero no sólo es la herencia, sino que el Código también marca claramente las formas de residencia, obligando a los cónyuges a vivir juntos y a los padres a tener con ellos a sus hijos.

Al hablar de modernidad hay una serie de autores que señalan cambios en el tamaño y estructura de la familia; otros dan mayor importancia a la variación de sus funciones y otros tienen en consideración las relaciones internas de sus miembros, fundamentalmente el tipo de vínculos que unen a la pareja conyugal. En virtud de estas variables van a determinar cuándo, en las diversas sociedades occidentales, se puede hablar de aparición de la familia moderna, en la creencia común de que la evolución de las formas familiares lleva en casi todas una dirección semejante, pudiéndose prever lo que ocurra, al menos en un futuro próximo.

Muchas veces se identifica la familia tradicional por la estructura y el número de sus miembros, pero esto no tiene por qué ser así. No se puede equiparar la familia amplia, en la que conviven personas de varias generaciones, con la familia tradicional. La frecuencia con que esto ocurre se debe a la conceptualización de LePlay sobre la familia. ${ }^{7}$ Este pensador social, preocupado por los efectos de la industrialización sobre la familia en Francia, idealiza la imagen de la familia troncal (famille-sucbe) que configura con todos los rasgos idealizados del Antiguo Régimen. Es la familia patriarcal y amplia, con un gran número de miembros de varias generaciones que conviven bajo la dirección del padre de familia o abuelo, al que obedecen. LePlay señala a esta familia, casi inexistente en la sociedad de su tiempo, como modelo de orden social y estabilidad y, por lo tanto, la más deseable socialmente.

Andrée Michel ha llevado a cabo un análisis detallado de los rasgos de esta familia tradicional de LePlay ${ }^{8} \mathrm{y}$, al especificarlos separadamente, ha puesto de manifiesto cómo muchos de ellos se encuentran en familias nucleares que, a pesar de su estructura diferente, mantienen muchos rasgos tradicionales en cuanto a las relaciones internas de sus miembros. ${ }^{9}$ Michel

5. J. L. Flandrin, op. cit., p. 70.

6. C. Lison, «Estructura antropológica de la familia en España», en Rof Carballo, La familia diálogo recuperable, Karpos, Madrid, 1976.

7. J. L. Flandrin, op. cit., p. 68.

8. A. Michel, Les cadres sociaux de la doctrine moral de Frederich LePlay, «Cahiers Internationaux de Sociologie», vol. 34, 1.963.

9. A. Michel, Modeles sociologiques de la fanille dans les sociétés contemporoines, en «Archives de Philosophie du Droit», Sirey, París, 1970. 
lleva a cabo una enumeración de los rasgos de la familia moderna como contraposición a estos rasgos tradicionales. En el modelo tradicional de familia hay una cristalización de funciones definidas estrictamente en función del sexo y la edad de los miembros de la familia sin tener en cuenta sus aptitudes $\mathrm{o}$ aspiraciones individuales. $\mathrm{Al}$ padre le corresponde la autoridad, el saber y el poder que se derivan fundamentalmente de su función económica: él será el que gana el pan de la familia. Él decide sobre los hijos, su trabajo, su matrimonio, y a éstos les corresponde la obediencia y el respeto. La dependencia de los niños y de los jóvenes con respecto a la familia se complementa con la dependencia de la mujer respecto del marido. Las relaciones conyugales son relaciones de dominio y de obediencia respectivamente. A la mujer le corresponde la vida doméstica y el cuidado de los hijos, sólo puede salir de este entorno por ausencia del marido. La función primordial de esta familia, el mantenimiento del orden social mediante el sometimiento de los jóvenes y las mujeres le hace oponerse a todo tipo de libertad individual; así el individuo se somete a la institución y hace de ella su destino. Se condena y se prohíbe el divorcio, la anticoncepción, el aborto y todo aquello que ayude a la emancipación de la mujer. ${ }^{10}$

Frente a éste, y por oposición, Michel señala las características deI modelo moderno (moderniste) de familia. Desaparece la diferenciación rígida de funciones ligada al sexo y a la edad; en esta familia cada individuo juega unos papeles según sus características personales y no de una forma predeterminada. Hay roles flexibles e intercambiables entre los cónyuges y entre padres e hijos según las circunstancias de cada momento. Tanto la autoridad como las responsabilidades domésticas tienden a intercambiarse entre los esposos; tanto la mujer como el marido pueden salir al exterior para ganar el sustento familiar, e incluso puede ser el marido el que cuide de lo doméstico. El papel educativo incluso puede intercambiarse con los hijos, siendo éstos los que en algunos momentos socialicen a sus padres. ${ }^{11}$ A la vez se rechaza la idea de sacrificio que implicaba el antiguo modelo familiar y se acepta la eventual ruptura del matrimonio. Se van abandonando las prohibiciones tradicionales, la cohabitación puede ser previa al matrimonio, la anticoncepción se generaliza dentro y fuera del matrimonio y se permite el aborto. Los jóvenes y las mujeres son los que más amplían su campo de libertad en este tipo de familia.

Frente a este análisis centrado en la adscripción de funciones de los miembros de la familia, nos encontramos con otro centrado en el modelo de autoridad. En su conceptualización de lo tradicional Flandrin nos ha-

10. Bis, pp. $128-130$.

11. Bis, pp. 131-132. 
bla de la familia «monárquica», cuyos rasgos predominantes son la autoridad del padre sobre los hijos y del marido sobre la mujer, estrechamente vinculados a subordinaciones religiosas. ${ }^{12}$ Según este autor, la familia nueva o moderna aparecería en Europa como consecuencia de la secularización, al reducirse la autoridad paterna y marital, prevaleciendo la familia «monárquica» en las sociedades más religiosas, en las que se mantendrían las relaciones más autoritarias entre padres e hijos y entre esposos. Flandrin señala el siglo xvirr como la época en que se empieza a cuestionar la autoridad marital y comienza a aparecer la imagen del compañerismo entre esposos. En cuanto a los padres y los hijos la ruptura de la relación vasallo-señor comienza más tarde y se va quebrando más lentamente. Las costumbres de autoridad, el poder del padre sobre el hijo, su poder económico, de hacerle trabajar, de castigarle, perviven hasta muy recientemente.

Otro intento de definir la modernidad lo lleva a cabo el historiador canadiense Edward Shorter, para quien la familia tradicional es aquella en la que los roles sexuales y el trabajo son muy diferentes para ambos cónyuges y el matrimonio no se decide por amor sino por interés. Aunque el primer aspecto, el de la diferenciación de roles, es común con el análisis de Michel, el modelo de Shorter es claramente diferente a aquél, en cuanto que considera el tema del afecto, del amor, la clave de la familia moderna. ${ }^{13} \mathrm{La}$ vida de la pareja conyugal viene marcada por la afinidad amorosa y la relación de camaradería, mientras que en un modelo anterior de familia lo que habían de hacer los esposos era atenerse cada uno a sus obligaciones. ${ }^{14}$

Shorter se encuentra entre los que consideran la modernidad como un hecho, definiendo con ello un cambio acaecido en una serie de cuestiones, fundamentalmente en la vida íntima, que hace desaparecer los rasgos de la sociedad tradicional. Los cambios en la vida íntima son difíciles de medir y Shorter intentará valorar algunos indicadores como la evolución de la actividad sexual premarital, la emergencia del libre albedrío en la decisión del matrimonio y la importancia del amor en la relación matrimonial. Las fechas que señala como hitos en esta transformación de la vida íntima son el siglo xvirr, con la mayor importancia dada a los sentimientos en el matrimonio, y mediados del siglo $\mathrm{xx}$, con la creciente valoración del sexo en las relaciones conyugales. El rasgo característico por antonomásia de la familia tradicional es la ausencia de sentimientos, la enorme distancia afectiva entre esposos y la ausencia de relación de afecto entre padres e hijos.

12. Flandrin, op. cip., pp. 154 y siguientes.

13. E. Shorter, El nacimiento de la familia moderna, Anesa, Buenos Aires, 1977.

14. Bis, pp. 70-95. 
Los comportamientos relativos entre cónyuges y entre padres e hijos vienen guiados por la costumbre que prescribe una serie de obligaciones sin que el afecto y el sentimiento tengan un lugar entre ellos. La relación amorosa como base de la decisión de matrimonio y el compañerismo entre esposos, rasgos de la modernidad por excelencia, aparecen lentamente a lo largo del siglo XVIII y XIX, convirtiéndose en un fenómeno generalizado sólo en la segunda mitad del siglo $\mathrm{xx}$. La importancia del sentimiento no se refleja sólo, según Shorter, en que el afecto y la compatibilidad mutua son las razones para elegir el cónyuge, sino que también se advierte en que, aun los matrimonios de interés, se comportan románticamente, como si ello fuera requisito indispensable para el matrimonio. La elección es cada vez más libre e individual por parte de los miembros de la pareja. El emerger del sentimiento presenta variaciones según las clases sociales. En las clases bajas se da una mayor sexualización de la pareja, mientras que en las clases medias serán el afecto materno y la domesticidad los rasgos de modernidad que antes se desarrollan, ya que implican riqueza y bienestar económico. Ambos se generalizan a todas las clases sociales a mediados del siglo xx. Esta familia es una unidad emocional. La domesticidad es el término clave para definir la familia moderna y en ello está incluido el afecto como guía de la elección conyugal, la privacidad y la estrecha vinculación afectiva entre padres e hijos.

Será René König el que añada a este intento de definición de la nueva familia un rasgo muy significativo, el cambio en la vida juvenil, en la infancia y la adolescencia. ${ }^{15}$ Aumenta la importancia de la socialización paralela: la guardería, la escuela, la televisión, que compiten con la influencia familiar. ${ }^{16}$ La más temprana emancipación económica y legal de los jóvenes coadyuva a la más temprana iniciación de las relaciones sexuales. König habla de la reducción de la edad de contraer matrimonio, fenómeno que se ha producido en Europa hasta 1970, en que de nuevo comienza a elevarse, como indicador de esa más temprana emancipación. Dentro de la familia aumentan los derechos de los hijos, el Estado incluso aparece en algunos casos como garante de estos derechos. En una línea similar a Shorter señala la creciente subjetivización de las relaciones familiares que devienen progresivamente afectivas. El ámbito emocional es el ámbito en el que la familia se mueve. ${ }^{17} \mathrm{La}$ evolución se caracteriza por un profundo proceso de individualización que hace pasar a primer plano las relaciones entre los cónyu-

15. R. König, La familia en nuestro tiempo, Siglo XXI, Madrid, 1981.

16. Esto ya lo señalaba Barrington Moore en una irónica visión de la evolución de la familia norteamericana. Poder político y teoría social, Anagrama, Barcelona, 1969.

17. R. König, op. cit., p. 75. 
ges. Habla incluso de familia conyugal porque la pareja no sólo representa la zona central de la familia, sino la permanente. Si ésta se rompe, con el divorcio por ejemplo, se dice que se rompe la familia. Paralelamente corre la creciente individualización de todas las relaciones en la sociedad. Dadas estas tendencias individualizadoras de la sociedad moderna, ${ }^{18}$ el matrimonio descansa primordialmente sobre la libre voluntad de los contrayentes, como se recoge actualmente en casi todas las legislaciones europeas; y más recientemente también ocurre lo mismo con su mantenimiento, al aparecer la fórmula de divorcio sin causa.

Aún señala König otro rasgo característico de la familia moderna, la importancia de la jerarquización entre hermanos ${ }^{19}$ lo que difícilmente puede aceptarse como tal, apareciendo más bien, a nuestro juicio, como un rasgo característico de los modelos familiares tradicionales. En la mayoría de las legislaciones actuales se iguala a todos los hijos en sus derechos y obligaciones respecto de los padres, y de tal modo impregna esto la costumbre social que apenas puede saberse de la colocación de un individuo dentro de su familia más que si lo consideramos en el terreno afectivo-conflictivo. Contrariamente a esta situación actual, en muchas sociedades tradicionales, como en las familias aristocráticas que son restos del Antiguo Régimen que aún quedan por Europa, la ley o la costumbre establece cuál ha de ser el status, los derechos y las obligaciones de los hijos, marcando una jerarquía en razón de edad y sexo y señalando diferentes papeles para cada uno. Otra cuestión, y esto es a lo que parece referirse König, es que la creciente importancia de los sentimientos en el entramado familiar explica muchos trastornos psicológicos por la situación del individuo en el seno de su familia, incluso en el orden cronológico de los hermanos. ${ }^{20}$

En base al análisis de la familia en las sociedades europeas, Louis Roussel elabora una tipología que pretende explicar la evolución de una serie de modelos familiares que han aparecido en la mayoría de las sociedades que contempla. ${ }^{21}$ Para elaborar su tipología tiene en cuenta fenómenos demográficos como la natalidad y la nupcialidad, comportamientos sociales como la diferenciación o no de funciones según el sexo, y la legi-

18. La modernidad viene a cortar lazos con lo comunitario, la ampliación de la libertad va en un sentido contrario al desarrollo de la comunidad. S. Giner, La estructura social de la Libertad, en «Revista Española de Investigaciones Sociológicas», número 11, julio-septiembre 1980.

19. R. König, op. cit., p. 87.

20. W. Toman, Family Constellation. Its effect of Personality and Social Bebaviour, Springer, New York, 1976.

21. L. Roussel, La crise de la famille, en «La Recherche», núm. 111, mayo 1980, pp. $544-553$. 
timidad de ciertas conductas como el divorcio, la anticoncepción, etc. En el modelo tradicional de familia la institución tiene mayor importancia y somete a los individuos; las relaciones sexuales sólo están permitidas entre cónyuges dentro del matrimonio; la ruptura del matrimonio es imposible salvo por muerte de uno de los cónyuges; la fecundidad es elevada al no haber o no permitirse la anticoncepción y tanto el hombre como la mujer tienen sus obligaciones específicas y diferentes dentro de la familia. A través de una flexibilización de las normas, acceso y permisividad de los anticonceptivos, posibilidad del divorcio, tolerancia de las relaciones sexuales prematrimoniales, etc., se va configurando una familia diferente, lo que él llama «la familia de hoy», que tiene una serie de rasgos, en unas ocasiones algo más extremados, y cuyas características principales serían: tolerancia de la cohabitación juvenil previa al matrimonio y generalización de la anticoncepción, incluido el aborto, que hace de la maternidad un hecho voluntario y permite reducir el número de hijos, así como marcar el calendario de los mismos. El matrimonio-fusión que lleva a este tipo de familia implica una vinculación emocional muy fuerte entre los esposos, lo que es origen al mismo tiempo de un número muy elevado de divorcios $\mathrm{y}$, posteriormente, de segundos matrimonios. El equilibrio de poder entre esposos en el seno de esta familia es bastante igualitario y también se igualan los roles exteriores a la familia del hombre y de la mujer. Este modelo de «familia de hoy» es el que aparece como predominante en Europa Central. A la vez, Roussel apunta un paso más allá en la evolución familiar que se observa en los países del Norte de Europa, en donde él cree ver un nuevo tipo de pareja conyugal, «el matrimonio-asociación», en el que la anticipación del posible fracaso de la unión conyugal ${ }^{22}$ lleva a los matrimonios a no invertir en dicha relación demasiado tiempo ni esfuerzo, por lo que, aunque motivada la unión por el sentimiento amoroso, ésta se parece más a una asociación en la que cada cual busca el máximo provecho posible, pero en la que no se ponen ya las esperanzas de realización personal y de satisfacción emocional más intensas. Con ello, la institución matrimonial pierde bastante de su importancia social, y sus alternativas como la cohabitación juvenil y el vivir en común sin matrimonio se generalizan produciendo casi los mismos efectos sociales; incluso se tienen hijos en estas uniones libres, hijos que tienen legalmente los mismos derechos que los matrimoniales, apareciendo una nueva forma de ilegitimidad: hijos en una situación legal irregular, pero con una vida cotidiana normal, pues tienen

22. J. Kellerhals y P. I. Troutot, On the relationsbip between divorce and matrimonial patterns, en «XIX CFR Seminar on Divorce and Remarriage», KUL, Lovaina, 1981. 
padre y madre al igual que los demás niños. ${ }^{23} \mathrm{El}$ número de matrimonios se reduce, la edad de contraerlo avanza y el número de divorcios es muy elevado. Aparecen numerosas variaciones de la familia nuclear: mujeres solas con sus hijos, hombres que comparten el hogar con grupos no unidos por un parentesco, etc., que erosionan el aspecto institucional de la familia. El matrimonio no se trata ya de una unión hasta que la muerte les separe (familia tradicional), ni de un proyecto para toda la vida (familia-alianza), $\mathrm{ni}$ de un proyecto con futuro (familia-fusión), sino de «ser felices juntos» ${ }^{24}$ mientras dure, una asociación que no confía demasiado en hacer planes para el día de mañana.

\section{ASPECTOS DEL CAMBIO FAMILIAR}

En nuestra búsqueda para saber la configuración de la familia española actual vamos a examinar la situación legal de una serie de cuestiones que los autores vistos anteriormente establecen en sus tipologías familiares como rasgos indicadores de la aparición de un tipo nuevo de familia. Analizaremos: 1. La religiosidad en relación a la institución familiar en cuanto se plasme en la normativa del Estado. 2. Las relaciones de autoridad entre los cónyuges como contrapuestas a las relaciones igualitarias. 3. Las relaciones de autoridad entre padres e hijos, así como el aumento de los derechos de los hijos. 4. La institucionalización del grupo familiar versus la flexibilidad de la formación de hogares no familiares y la tolerancia de comportamientos alternativos a la familia. 5. La importancia de la voluntad individual en la formación de la pareja. 6. La diferenciación de funciones entre los cónyuges o la eventual intercambiabilidad de los mismos. 7. El control de la natalidad y la libertad de decisión sobre la misma. 8. La posibilidad y modalidades de romper el matrimonio.

\section{Influencia de la Iglesia en la normativa matrimonial}

El nivel de religiosidad en un determinado momento histórico puede verse en las formas matrimoniales que se adopten según la validez que en ellas se conceda al matrimonio religioso. Hay cuatro sistemas matrimoniales posibles: sistema de matrimonio religioso, de matrimonio civil facultativo,

23. K. Aromaa, Cohabiting families, comunicación a la VII Reunión del Grupo Internacional de Investigaciones sobre el Divorcio, Madrid, noviembre, 1980.

24. L. Roussel, op. cit. 
de matrimonio civil subsidiario y de matrimonio civil obligatorio, según la posición adoptada por el Estado respecto a los poderes religiosos. Se habla de sistema de matrimonio religioso cuando el Estado considera que la Iglesia es la única potestad competente para regular el matrimonio y deja en sus manos todo lo que a él respecta, imponiéndose como única forma posible de casamiento el matrimonio religioso. El sistema del matrimonio civil obligatorio supone todo lo contrario; se define que el único competente en cuestiones matrimoniales es el Estado y sólo se reconoce el matrimonio civil, ignorándose legalmente los matrimonios contraídos según las diversas confesiones religiosas. El sistema de matrimonio civil subsidiario supone una preeminencia religiosa pero no totalizadora en el tema matrimonial y suele ir unido a la identificación del Estado respecto a una determinada confesión religiosa. Deberán contraer matrimonio religioso, según la religión reconocida por el Estado, todos aquellos que pertenezcan a la misma, pudiendo tan sólo celebrarse un matrimonio civil entre aquellos que no pertenezcan a ninguna confesión religiosa o a una que no esté reconocida; este matrimonio religioso produce plenos efectos civiles.

El sistema de matrimonio civil facultativo es cuando el Estado deja en libertad a sus ciudadanos para elegir la forma que deseen para contraer matrimonio, pudiendo optar ya sea por el matrimonio religioso conforme a sus creencias, o por el matrimonio civil conforme a la ley estatal; ambos producen los mismos efectos civiles. Ésta es la fórmula actualmente en vigor en España.

Hasta muy recientemente el peso de la religiosidad era patente en España, el Estado se declaraba confesional y ello repercutía en la familia. Hasta 1978 el matrimonio civil subsidiario era la norma y a los católicos les era preciso apostatar para contraer matrimonio civil. La Constitución de 1978 establece la separación de la Iglesia y el Estado y declara el Estado aconfesional. Este cambio en la relación con la Iglesia es enorme, y supone no sólo secularizar el pacto matrimonial, ${ }^{25}$ sino también la posibilidad de cambiar otros aspectos matrimoniales como la filiación, la patria potestad, el régimen económico matrimonial y la posible disolución del mismo. Pero la separación de la Iglesia y el Estado en temas familiares no es total; el mantenimiento de ciertas prerrogativas de la Iglesia Católica como la competencia de los Tribunales Eclesiásticos en materia de nulidad matrimonial influye aún decisivamente en nuestra sociedad. El peso de la Iglesia sobre las conciencias, reforzado por el poder temporal de la misma, pesa aún de

25. Cristina Alberdi, La institución matrimonial y su lugar en la constelacion familiar, comunicación a las I Jornadas de Sociología de la Asociación Castellana de Sociología, Madrid, mayo 1980. 
modo significativo en la sociedad española. A partir de 1979 , cuando se deroga Ia obligación de llevar las separaciones matrimoniales ante los Tribunales Eclesiásticos, éstos luchan por conservar el tema de las anulaciones. Las nulidades matrimoniales se han convertido en una práctica encubierta de divorcio religioso, aun antes de que existiera el divorcio civil, al ser la única forma aceptada por la Iglesia de romper un matrimonio, y sus cifras crecieron enormemente en los últimos años. ${ }^{26} \mathrm{La}$ alta burguesía, y sobre todo los sectores más religiosos de ella, acude a estos tribunales, que son los únicos que hacen posible un segundo matrimonio religioso.

$\mathrm{El}$ sistema de matrimonio civil subsidiario persiste hasta 1981. Con la reforma del Código Civil de julio de 1981 el Estado adopta una fórmula más secularizada, el matrimonio civil facultativo; los ciudadanos pueden optar por casarse civilmente o según su propia confesión religiosa; la Iglesia pierde sus poderes para decidir sobre la separación matrimonial de sus fieles y sus tribunales sólo tienen atribuciones para dictaminar la validez o nulidad de los matrimonios. De la separación y el divorcio sólo entienden los tribunales civiles, ya se trate de matrimonios religiosos o civiles (art. 85).

Desde un punto de vista legal esa modernización es similar a la que llevó a cabo la Segunda República española; incluso las prerrogativas de la Iglesia quedaron más recortadas entonces. Pero no podemos decir que la situación actual tenga nada que ver con aquella referente al tema que nos ocupa. Mientras que en los años treinta se intenta modernizar la sociedad a golpe de decreto, en los primeros ochenta lo que hacen los legisladores es sancionar, legitimar en las leyes, lo que es una realidad evidente, la secularización de la sociedad española. Podríamos decir que, aunque la ley y la sociedad dejan mucho espacio de actuación a la Iglesia Católica, la pérdida de religiosidad ha sido significativa en España. ${ }^{27}$

\section{Relaciones de autoridad y de igualdad entre los cónyuges}

En lo que respecta a las relaciones entre los cónyuges el cambio legal ha sido enorme. Se parte de una familia fuertemente jerarquizada en la que la autoridad del varón, padre y esposo, está marcada claramente en los textos legales. En 1970, con ocasión de algunas reformas que ampliaban la capacidad de obrar de la mujer casada (Ley 4 julio 1970), aún se decía: «Se contempla, por tanto, la posición peculiar de la mujer casada en la

26. Guia de la Iglesia en España, 1979, 1980, Madrid.

27. Informe sobre la situación social de España, «Foessa», 1975. 
sociedad conyugal, en la que, por exigencias de la unidad matrimonial, existe una potestad de dirección que la naturaleza, la religión y la historia atribuyen al marido.» Esto ha cambiado totalmente en la reforma del Código Civil de 1981, que marca una estructura igualitaria de relaciones entre el hombre y la mujer en el seno del matrimonio.

Hasta 1975 la mujer debía obediencia al marido, que había de prometer en el momento de casarse, y el marido a cambio tenía que protegerla. En la reforma del Código Civil de 1975 se establecía «El marido y la mujer se deben respeto y protección recíproca», abandonando las anteriores fórmulas de subordinación. Los deberes de los cónyuges respecto de la familia se establecían iguales para ambos (arts. 56 y 57), pero, sin embargo, determinados derechos eran prioritarios del hombre, como el de la determinación del hogar conyugal (art. 58), pues se establecía que el domicilio lo deciden ambos cónyuges de común acuerdo, pero en caso de desacuerdo corresponde la decisión a aquel que tenga la patria potestad sobre los hijos, y poco más allá, en la misma ley, se establecía que la patria potestad corresponde al padre y sólo en su defecto a la madre (art. 154). Estas prerrogativas masculinas desaparecen con la ulterior modificación del Código Civil (Ley 28 abril 1981 y Ley 7 julio 1981). El domicilio lo deciden entre ambos cónyuges y en caso de desacuerdo ha de ser el juez el que medie entre ambos.

Hay otro aspecto en el que también ha variado la situación de la mujer en estos últimos años, y es en lo que respecta a la autonomía económica de la esposa. La mujer casada puede trabajar, abrir un comercio y comprar y vender sin necesidad de pedir autorización ni licencia de su marido como ocurría hasta la reforma del Código del Comercio (2 mayo 1975). A partir de 1975 se abre la posibilidad de que los cónyuges hagan capitulaciones matrimoniales entre ellos regulando sus relaciones económicas, posibilidad esta que ya reconocía el derecho foral en Cataluña. Con la reforma de 1981 el régimen económico del matrimonio ya no viene impuesto, sino que se deja a la libre voluntad de los cónyuges, que pueden variarlo por mutuo acuerdo en cualquier momento de su matrimonio (art. 1315). Hasta 1981 el marido era el único administrador de los bienes gananciales del matrimonio; el Código Civil equiparaba a la mujer casada con los subnormales en cuanto a la pérdida de la capacidad de obrar. En 1970 se pretende ampliar esta capacidad de la mujer casada estableciendo que el marido, aunque único administrador de los bienes familiares, ha de pedir el consentimiento de la mujer para las actuaciones de compra y venta de bienes de cierta envergadura. Ya en 1975 se cambia algo la situación; el marido sigue siendo el único administrador de los bienes familiares, pero la mujer adquiere autonomía para administrar sus bienes propios, desaparece la ne- 
cesidad de obtener la licencia del marido para disponer de sus bienes propios (arts. 59-63).

A partir de las reformas de 1981 la administración de los bienes familiares corresponde a ambos cónyuges (arts. 1316 y 1375). El régimen económico del matrimonio es el de gananciales, si no hay pactos específicos entre los esposos que dispongan otra cosa. La sociedad de gananciales supone la propiedad igualitaria de todos los bienes y ganancias del matrimonio entre ambos cónyuges (art. 1344). En caso de separación la mitad de todos los bienes del matrimonio, ya sean fruto de negocios o fruto del trabajo personal, corresponde a cada uno de los esposos, ya sea que ambos trabajen en estas actividades o lo haga uno solo de ellos. Lo que permite la reforma reciente es que los esposos pacten entre sí otro tipo de acuerdo económico, el que deseen, siempre que no sea contrario a derecho. La pretensión igualitaria de la Ley en lo que respecta a los derechos del hombre y de la mujer dentro del matrimonio se pone de manifiesto en el artículo 1328 del Código Civil que impide que los esposos pacten entre sí algo que altere esta igualdad de derechos.

Hay otro aspecto en que las leyes tienden a configurar una relación igualitarista en el seno del matrimonio en contradicción con situaciones pasadas, y es en lo referente a las normas de fidelidad matrimonial. Uno de los deberes mutuos del matrimonio, según la reciente reforma, es el de guardarse fidelidad (art. 68), sin aclarar qué se entiende por fidelidad, pero también sin hacer distinciones en cuanto a la conducta infiel en el hombre y la mujer. Hasta muy recientemente el Código Penal tipificaba como delito el adulterio, diferenciando entre las conductas que podían considerarse adulterio en el hombre y en la mujer, dando prioridad para ello al concepto del honor familiar por encima de la mera conducta sexual. El adulterio lo cometían «la mujer casada que yace con varón que no sea su marido y el que yace con ella sabiendo que es casada» y se castigaba con prisión menor, mientras que obtenía el mismo castigo «el marido que tuviera manceba dentro de la casa conyugal o notoriamente fuera de ella». El lenguaje que emplea y la severidad del castigo nos hace difícil creer que fue una norma en vigor hasta 1978. Con su derogación no se hizo otra cosa que ajustar la ley a la realidad social; era una norma más simbólica que real, aunque a veces se recurría a ella en los pleitos de separación matrimonial. En la reforma del Código Civil sobre separación matrimonial y divorcio aparece la infidelidad conyugal como causa de separación (art. 82), pero no hay ninguna referencia al término de adulterio ni se hace distinción entre la conducta del marido y de la esposa. También en la línea del igualitarismo sexual podemos ver la mayor responsabilidad masculina sobre la concepción que puede ser exigida ante los tribunales. El juez puede determinar 
la paternidad, si hay pruebas, aunque el hombre se oponga a ello (arts. 115120). La investigación de la paternidad mediante toda clase de pruebas, incluidas las biológicas (art. 127), es una novedad importante en nuestro ordenamiento jurídico, que, tradicionalmente, no aceptaba reclamaciones de reconocimiento de la paternidad por parte de madres solteras ni aceptaba el reconocimiento de un hijo de mujer casada por otro hombre que no fuera su marido. Con esta reforma se equipara por vez primera al hombre y a la mujer en cuanto a las responsabilidades derivadas de su conducta sexual. Bien es cierto que en la sociedad aún se valoran de un modo diferente los mismos comportamientos sexuales en el hombre y en la mujer.

\section{Autoridad de los padres y aumento de los derechos de los bijos}

En el tema de la autoridad familiar con respecto a los hijos las leyes actuales son decididamente igualitarias al reconocer los derechos del padre y de la madre. Ambos cónyuges tienen los mismos derechos y obligaciones respecto de los hijos (art. 154). La patria potestad de los padres que viven juntos es compartida, es decir, ambos tienen la misma autoridad sobre los hijos. A ellos les corresponde ponerse de acuerdo en todas las decisiones que conciernen a sus hijos menores no emancipados. En caso de desacuerdo pueden acudir al juez, y en caso de separación la patria potestad corresponderá a aquel con el que convivan los hijos, a no ser que pacten entre ellos otra cosa (art. 156). Antes de la reforma de 1981 la patria potestad correspondía siempre al padre, que sólo podía perderla por causa grave, dándose numerosos casos de matrimonios separados cuyos hijos, aun viviendo con la madre, dependían de la autoridad del padre, lo que ocasionaba muchos problemas. Actualmente, tanto el padre como la madre pueden perder la patria potestad sobre los hijos por una serie de razones graves, entre ellas el hombre que se oponga a reconocer un niño y posteriormente los tribunales lo declaren hijo suyo (art. 111). Pero aun en el caso de pérdida de la patria potestad se mantienen los deberes y obligaciones respecto a velar por ellos y prestarles alimentos.

$\mathrm{La}$ autoridad de los padres siempre ha estado compensada por las obligaciones de éstos con respecto a los hijos. Si en la familia tradicional tiene mayor fuerza el peso de la autoridad paterna, el aumento de la autodeterminación de los hijos que se refleja en las recientes reformas del Código Civil español (28 abril 1981 y 7 julio 1981) es un rasgo de una familia diferente. La mayoría de edad está fijada en los 18 años, de forma similar a lo que ocurre en Europa, pero aun en estos años en que el hijo depende de los padres sus decisiones tienen un cierto valor en algunas cuestiones. En 
caso de separación de los padres el juez ha de escuchar al hijo que tenga 12 años o más, antes de decidir con cuál de los padres debe vivir; y puede escucharlo, aunque no es preceptivo, a partir del uso de razón. Al llegar a la mayoría de edad los hijos pueden tomar una serie de determinaciones que contradigan las que sus padres tomaron por ellos mientras los tuvieron bajo su tutela. Los hijos no matrimoniales pueden rechazar el reconocimiento de la paternidad hecho por su progenitor (art. 137), y el reconocimiento de un hijo mayor de edad no surte efecto hasta que éste lo acepte (art. 123). Los hijos matrimoniales pueden, al llegar a la mayoría de edad, cambiar el orden de sus apellidos. Con esto se abre la posibilidad de continuación de los apellidos maternos y es de lamentar que la reforma no haya contemplado la posibilidad de los padres de elegir el orden de los apellidos, pues el sistema actual de adjudicación de apellidos, primero el del padre y luego el de la madre, aunque más igualitario que el predominante en Europa -donde se pone a los hijos únicamente el apellido del padre y donde hasta incluso la mujer lo pierde al casarse tomando el de su marido- evita la desaparición del nombre materno en la primera generación, pero lo hace desaparecer en la segunda. Con la libertad de elegir el apellido materno al llegar a la mayoría de edad desaparece la connotación de deshonra social que tenían los que llevaban los apellidos maternos.

Hay una pérdida de la autoridad del padre, no sólo en cuanto comparte la autoridad con la madre, sino incluso por las limitaciones que la ley impone a esa autoridad. La patria potestad implica más deberes que derechos; los padres han de velar por los hijos, tenerlos en su compañía, educarlos y alimentarlos (art. 154): Las atribuciones de autoridad quedan también limitadas legalmente, «podrán corregir razonablemente y moderadamente a los hijos» (art. 154). Los hijos a su vez han de obedecer a sus padres y respetarles, así como contribuir «equitativamente» a las cargas de la familia mientras vivan con ella. La ley establece muchas cautelas para evitar que los padres abusen económicamente de los hijos (arts. 162-168). La mayoría de edad queda establecida en 18 años, edad relativamente temprana, igual a la que predomina en los países europeos más desarrollados y que ayuda a configurar una familia que va reduciendo su etapa de maternidad y cuidado de los hijos. ${ }^{28}$ Antes de 1978 la mayoría de edad estaba marcada a los 21 años, e incluso hasta 1972 se hacía una excepción a esta norma, pues las «hijas de familia» no alcanzaban la emancipación respecto de su padre hasta que cumplían los 25 años (art. 321 del Código Civil derogado en julio de 1972). La mayoría de edad revestía una mayor

28. S. del Campo, El ciclo de vida de la fanilia española. Real Academia de Ciencias Morales y Políticas, Madrid, 1980. 
importancia, ya que los hijos menores habían de obtener licencia del padre para contraer matrimonio, y aun los mayores de edad debían pedir consejo al padre, debiendo posponer el matrimonio por tres meses si éste se oponía. La licencia matrimonial desaparece en la reforma de 1981, pero se mantiene la necesidad de emancipación para que un menor pueda contraer matrimonio.

\section{Institucionalización del grupo familiar}

El proceso de desinstitucionalización no aparece más que en sus inicios si lo juzgamos a partir del análisis de la legislación. Tanto el matrimonio como la familia son instituciones muy importantes en la sociedad española, y toda una serie de costumbres, ceremonias y leyes así lo reflejan. Actualmente hay una mayor flexibilidad normativa en cuanto aparece por primera vez la tolerancia ante ciertas conductas que, si antes aparecían, iban acompañadas de estigmatización social. Es el caso, fundamentalmente, de las concepciones fuera del matrimonio, que la ley no podía impedir, pero que eran señaladas como ilegítimas y conllevaban la pérdida de una serie de derechos. En 1981 desaparece la diferencia entre los hijos por razón de la situación matrimonial de los padres. Todos los niños tienen los mismos derechos con respecto de sus padres, que son los derechos de reconocimiento, atención económica y cuidado personal, así como a la herencia futura de sus bienes. $\mathrm{Y}$ en cuanto a la denominación sólo se distingue entre hijos matrimoniales y no matrimoniales, la diferencia entre ambos no existe más que en aquellas circunstancias personales que les permita o impida vivir en común con los padres. Por otra parte, no hay ningún inconveniente legal para aquellas parejas que deciden vivir juntos sin contraer matrimonio, salvo que no obtienen los derechos que el matrimonio conlleva, como son los relativos a los bienes o las pensiones. Lo que no aparece aún en la legislación española es la equiparación de estos derechos entre parejas que viven juntas sin matrimonio y aquellas que son matrimonio, como, por ejemplo, derecho a atención médica o a pensiones o a indemnización por separación, que empieza a verse en algunos países del norte de Europa. Si hiciéramos un balance de las ventajas que aún se ofrecen con el contrato matrimonial ${ }^{29}$ podríamos decir que las leyes actuales refuerzan la institucionalización del matrimonio más que lo contrario, aunque el proceso de cambio ha empezado. Sólo en las medidas económicas derivadas del divorcio

29. Recientemente hacía este tipo de comparaciones una revista de Madrid. Gloria Otero, ¿Casado o juntos?, «El País Semanal», 25 de abtil de 1982. 
se contempla la posibilidad de obtener pensión de viudedad por haber vivido con un hombre por largo tiempo en igualdad de derechos con la esposa legítima, hablando la ley de repartir el monto de la pensión en proporción directa al número de años que haya vivido cada una con dicho hombre, medida que tiende a quitar peso institucional al matrimonio. Otra medida que también va en el sentido de equiparar el matrimonio y otras formas alternativas es la posibilidad que introduce la reforma de 1981 de reconocimiento de paternidad de un hijo de mujer casada por otro que no sea su marido, sin que medie pleito de separación matrimonial. Éste ha de hacerse, mediante las declaraciones pertinentes, antes de los seis meses de la vida del niño (art. 117), y refleja la mayor flexibilidad institucional de la familia en cuanto la ley contempla posibles situaciones diferentes a las prescritas en el matrimonio.

En cuanto a la forma de la institución familiar, la ley no prescribe pero delinea cómo ha de ser ésta. Legalmente se privilegia la institucionalización de la familia nuclear frente a modelos más amplios y familiaristas. El modo como señala que los esposos han de vivir juntos (art. 68) y que los hijos han de vivir con sus padres (art. 154) señala como forma básica de familia la del matrimonio que vive con sus hijos, es decir, una estructura nuclear. La forma nuclear de familia también queda dibujada en el Código cuando se establecen las obligaciones económicas entre parientes, como la reclamación de alimentos y la educación en el caso de los menores (art. 143). Son los cónyuges, en primer lugar, los obligados entre sí; en segundo lugar, los descendientes de grado más próximo, es decir, los hijos y en su defecto los ascendientes más próximos, es decir, los padres, y en cuarto lugar los hermanos (art. 144). De modo que la persona no puede recurrir legalmente más que a los que han formado con ella una familia nuclear en algún momento. Supongamos, por ejemplo, una mujer soltera mayor cuyos padres han fallecido y cuyos hermanos han fallecido dejándole un gran número de sobrinos, y que no tiene hijos propios; a la hora de pedir alimentos a sus parientes no tiene apoyo legal.

\section{La importancia de la voluntad individual}

La importancia de la voluntad individual en la formación de la pareja queda claramente marcada en las normas matrimoniales, pues a partir de 1981 es uno de los requisitos del matrimonio. Ya han pasado muchos años desde que los padres eran los que determinaban el cónyuge y acordaban el matrimonio de los hijos. A la sensibilidad actual ofende el forzar el matrimonio involuntario entre dos individuos; no han desaparecido las 
presiones, influencias y condiciones para ganar la voluntad de los individuos que se desea encaminar hacia el matrimonio, pero es preciso que esas presiones convenzan, ya no vale la mera imposición, pues la voluntad es uno de los requisitos necesarios para que un matrimonio sea válido (art. 45). «No hay matrimonio sin consentimiento individual.» $\mathrm{La}$ importancia del consentimiento es tal que su ausencia convierte en nulo el matrimonio (art. 73). Es importante señalar la ausencia de la autoridad de los padres o de la familia en la decisión de casarse, han desaparecido las licencias matrimoniales y tampoco son válidas otro tipo de influencias, pues si existen coacciones el matrimonio es nulo.

También se refleja la creciente importancia de la voluntad individual, respetada por la ley en la regulación de la separación matrimonial y el divorcio. La separación matrimonial puede solicitarse por acuerdo mutuo de los cónyuges (art. 81), y en este caso el juez no puede denegarla, sólo tiene atribuciones para revisar el convenio regulador que éstos hayan establecido entre ellos, a fin de conocer que no es contrario al interés de los hijos. En cuanto al divorcio, la ley no contempla la posibilidad de divorcio por acuerdo mutuo de los cónyuges, pero si la separación se ha llevado de acuerdo mutuo, el tiempo que ha de transcurrir para solicitar el divorcio es mucho más reducido (art. 86).

\section{Equiparación de los roles en la pareja matrimonial}

En cuanto a la diferenciación de roles como un rasgo de tradicionalismo, podemos verlo aparecer en numerosas ocasiones en las familias españolas, pero en muy pocos casos se refleja en los textos legales. El informe Foessa de 1975 reflejaba una pareja conyugal muy separada en sus funciones y responsabilidades, ocupándose la mujer de la vida doméstica y el hombre de trabajar fuera de casa, así como de tomar las decisiones familiares que no aparecen como cotidianas..$^{30}$ Esto también se reflejaba en las leyes de entonces, pero con la reforma de mayo de 1975 y las dos reformas de 1981 ha desaparecido este modelo dual del texto de la ley. La mujer es sujeto de todos los derechos tanto políticos como familiares y laborales y su situación no cambia por el matrimonio. Sólo encontramos ciertos aspectos legales, poco numerosos, en los que aparece como telón de fondo esa separación de funciones entre hombre y mujer que, sin embargo, a nivel cotidiano observamos tan frecuentemente. Por ejemplo, en la regulación de la filiación y la paternidad (ley abril 1981) se define que, cuando los padres vivan separados,

30. A. de Pablo, La familia española en cambio, «Foessa», Madrid, 1975. 
los hijos e hijas menores de siete años quedarán con la madre, a no ser que decidan otra cosa de común acuerdo o que el juez tenga razones para decidir otra cosa (art. 159). El atribuir los hijos, sobre todo los pequeños, a las mujeres es un rasgo muy común en la mayoría de las leyes de divorcio y responde a una realidad muy extendida de ser las mujeres las que cuidan y atienden personalmente a los hijos, pero la sanción legal de esta práctica es un respaldo tácito a la fuerte diferenciación de funciones que aparece entre el hombre y la mujer en la familia, rasgo determinante de la vida tradicional.

Encontramos otro aspecto legal que viene a sancionar una adscripción de funciones diferenciada según el sexo en la normativa de los derechos sociales de los trabajadores. Según la ley de Seguridad Social, la mujer trabajadora no produce derechos de viudedad ni de orfandad, a pesar de cotizar igualmente que su colega masculino. Detrás de esta norma hay una infravaloración del papel de trabajadora de la mujer, que además es esposa y madre, suponiendo el legislador que no hay que compensar a las familias que dejen de percibir sus ingresos, en una norma que, además de suponer una injusticia retributiva, desvaloriza el papel de la mujer como trabajadora (decreto 2.065, 30 mayo 1974).

\section{Control de la natalidad}

El control de la natalidad aparece como uno de los indicadores más frecuentemente usados para definir la familia moderna. Los modelos tradicionales de familia son natalistas desde proposiciones negativas, prohibiendo todo tipo de medidas anticonceptivas y valorando positivamente el elevado número de hijos. Ésta ha sido también la teoría de la Iglesia Católica sobre el tema. Los hijos son en algunas sociedades un enriquecimiento familiar en cuanto suponen la promesa de trabajo posterior en la explotación familiar agrícola o artesana. En otras sociedades, como las sociedades industriales actuales, los hijos representan más un aumento de gastos que una previsión de ingresos; su mantenimiento y educación suponen mayor cantidad de gastos cuanto más rica y desarrollada sea la sociedad de que se trate. $Y$ esto, unido a la más temprana independencia de los mismos, hace que el tener hijos aparezca como un valor de enriquecimiento personal y humano, peto no económico. Las motivaciones para tener hijos son de lo más variado y el tenerlos deviene cada vez más un asunto de decisión personal de la pareja que un acontecimiento regulado por la obligación o la costumbre. Esta situación ha sido posible por el descubrimiento y la popularización de diversos métodos anticonceptivos. En Europa la generalización de los anti- 
conceptivos, que ha venido unida a la voluntariedad de su uso por miles de mujeres, ha sido uno de los factores que más han ayudado a configurar un tipo de familia diferente. ${ }^{31}$ La familia española sería en este terreno bastante tradicional, si nos atenemos a la normativa vigente, al estar el uso de los anticonceptivos muy dificultado y el aborto totalmente prohibido. Nuestra hipótesis es que el uso de los anticonceptivos y del aborto supera ampliamente las barreras legales que se le presentan.

El uso de los anticonceptivos está muy generalizado en España, pero el conocimiento y acceso a los mismos está muy condicionado por el nivel cultural de la mujer, dada la forma restrictiva de su difusión. La venta, uso y difusión de los anticonceptivos han estado prohibidos y penalizados hasta muy recientemente. Hasta 1978 sólo una minoría de mujeres han utilizado, bajo cuerda, los métodos más cómodos y seguros de anticoncepción como el diafragma o los dispositivos intrauterinos; la píldora se utilizaba ampliamente, a pesar de la legislación, gracias a que podía considerarse una medicación adecuada en algunos trastornos femeninos, mientras una gran cantidad de mujeres, sobre todo de las capas más pobres de la población, guardaban un difícil equilibrio entre el coito interrumpido, el preservativo masculino y el embarazo no deseado. La enorme cantidad de fallos, es decir, de embarazos no deseados, refleja que el control de la natalidad era más bien rudimentario. ${ }^{32}$

Cuando en 1978 se despenalizan los anticonceptivos, se regula su uso e información de un modo muy restrictivo y, lo que es más importante, no se introduce la anticoncepción en los servicios médicos de la Seguridad Social. Los seguros sociales no tienen servicios de «planificación familiar», como eufemísticamente se llama en España al control de la natalidad, con lo que se dificulta su uso a las mujeres de las clases sociales más bajas, a las que supone un fuerte desembolso acudir a clínicas privadas para obtener la atención necesaria. Para paliar estas circunstancias se han creado clínicas gratuitas de planificación familiar por parte de asociaciones ciudadanas, ayuntamientos de izquierda y grupos feministas, pero su número es aún muy reducido; también es cierto que muchos médicos de la Seguridad Social atienden en ginecología a consultas de planificación familiar.

En cuanto al aborto, el Código Penal lo reprime rígidamente (arts. 411 . 417). Se condena a penas de prisión mayor o menor, según el consenti-

31. A. Myrdal, La mujer y la sociedad contemporánea, Península, Barcelona, 1973.

32. J. Díez Nicolás, Actitudes de la mujer española bacia los métodos de planificación familiar, «Revista Española de la Opinión Pública», núm. 31, 1973. A. de Miguel, Sexo, mujer y natalidad en España, Edicusa, Madrid, 1974. J. M. de Miguel, Sociología de la población y control de la natalidad en España, «Revista Española de Investigaciones Sociológicas», núm. 10, 1980. 
miento de la mujer a la que se le provoque un aborto; y si se trata de un profesional de la medicina se le inhabilitará para el ejercicio de la profesión. A la mujer que se produzca un aborto o que consienta en que otro lo haga, también se la condena a prisión, salvo cuando «se lo cause para evitar su deshonra», en que las penas serán sólo de arresto mayor. En este tema el Código Penal refleja una visión absolutamente tradicional y sexista del embarazo de la mujer, pues no contempla ninguna de las indicaciones aceptadas en los países que han regulado recientemente el aborto (peligro de la vida de la mujer o de trastornos psicológicos graves, inviabilidad del feto para llegar a ser una criatura normal, violación como origen del embarazo, etc.), sino tan sólo la posible mancha del honor familiar, suavizando su rigor cuando el aborto busca ocultarla. Por otra parte, el aborto es en España una realidad innegable en los últimos años. Las modalidades del aborto varían según la clase social, las mujeres de las clases sociales más bajas abortan clandestinamente en España en condiciones de higiene y seguridad muy deficientes, y las mujeres de clases medias, o al menos de un cierto nivel cultural, lo hacen en clínicas europeas con métodos más seguros

y menos dolorosos. La rigidez de la norma legal en contraste con la realidad social tolerante se ha puesto de manifiesto recientemente en el debate público originado con motivo del juicio de Bilbao, en el mes de marzo de 1982, de unas mujeres obreras acusadas de haberse provocado abortos. Por primera vez la sentencia judicial ha tenido en cuenta «el estado de necesidad» de estas mujeres, que se ven impelidas a interrumpir sus embarazos, de un modo similar a como lo contemplan las legislaciones europeas que han liberalizado el aborto. ${ }^{33}$

\section{La ruptura del matrimonio}

No sólo la existencia o no del divorcio, que es definitivamente la clave de la ruptura con una familia tradicional anclada en la idea del sometimiento personal al destino, sino también la forma y modalidades de acceder al mismo, nos indican el modelo de familia que se da en una determinada sociedad. Si el divorcio es clave en la configuración de la familia moderna, España acaba de traspasar este umbral, pues después de más de cuarenta años de absoluta imposibilidad de disolver un matrimonio se introduce el divorcio vincular mediante una reforma del Código Civil.

El divorcio sanciona legalmente la libertad individual de romper el

33. J. Iglesias de Ussel, El aborto: un estudio sociológico sobre el caso español, Centro de Investigaciones Sociológicas, Madrid, 1979. 
matrimonio, ya sea por conducta culpable de uno de los cónyuges (divorciosanción), para evitar males mayores o corregir errores (divorcio-remedio), o por deseo de un cambio en la situación personal de los cónyuges sin explicar los motivos que les llevan a ello (divorcio voluntario o de común acuerdo). Las diferentes fórmulas legales del divorcio configuran modelos familiares diferentes, pues en unas se dificulta más que en otras la ruptura, colaborando al mantenimiento del matrimonio en detrimento de la libertad de los cónyuges en mayor o menor medida.

El divorcio que se introduce con la reforma de 1981 es moderado pero no conflictual, en cuanto que exige, para la disolución definitiva del matrimonio, el transcurso de una serie de tiempo que lo retrasa forzosamente, pero la tramitación del mismo no implica necesariamente el pleito entre los esposos ni la demostración de culpabilidad de ninguno de ellos; además, todo el procedimiento del divorcio se simplifica si ambos cónyuges se ponen de antemano de acuerdo sobre los términos de su ruptura matrimonial. Según la ley, la separación ha de ser siempre previa al divorcio, se puede solicitar de común acuerdo (sin explicar las razones) o por determinadas causas, y supone la separación de bienes y de domicilio entre los esposos. Una vez separados, hay que dejar transcurrir unos ciertos períodos de tiempo, más largos cuanto más en desacuerdo estén los esposos en separarse, pasados los cuales se puede pedir el divorcio. El divorcio supone la disolución total del vínculo y la posibilidad de contraer nuevo matrimonio. Con esta ley no es difícil divorciarse, pero es lento, el tiempo necesario oscila entre un año y cinco años que necesitará el que tome la decisión del divorcio contra la voluntad de su cónyuge y su oposición activa. La ley deja una libertad total a los cónyuges para que negocien los términos de su ruptura - el convenio regulador en el que acuerdan la custodia de los hijos, el régimen de visitas, el uso del domicilio familiar, el reparto de los bienes y las pensiones alimenticias si las hay- y el juez sólo interviene si no llegan a un acuerdo. Es un divorcio moderno en cuanto deja en libertad al individuo no sólo para romper su matrimonio, sino también para establecer cuáles van a ser las relaciones posteriores entre él y su antigua familia. No se reconoce el mutuo acuerdo como fórmula de divorcio, que aparece en la mayoría de las legislaciones europeas actuales, péro de hecho la pareja que va de acuerdo mutuo a pedir el divorcio lo obtiene de una forma más simplificada y rápida. 


\section{LA FAMILIA NUEVA}

Haciendo una valoración del modelo familiar imperante en España, tan sólo a nivel de legislación, podemos afirmar que se trata de una familia moderna. Se han producido grandes cambios legales que han ayudado a configurar una familia más similar a modelos europeos, aunque aún subsisten una serie de aspectos tradicionales como la influencia de la Iglesia en el ordenamiento matrimonial; la orientación diferenciadora de funciones en algunas normas laborales; la dificultad en el uso y difusión de los anticonceptivos y la prohibición del aborto, que separan el modelo familiar español de sus homólogos europeos.

No podemos hablar de la vigencia en España de la familia tradicional. Hay muchos y muy importantes rasgos de una familia nueva, la igualdad entre los cónyuges, la suavización de las relaciones de autoridad, la posibilidad del divorcio, la equiparación educativa de hombres y mujeres, su posible acceso a toda clase de profesiones, etc., que nos indican que el proceso de modernización está muy avanzado en la legalidad familiar de nuestro país. Hay que reconocer el enorme esfuerzo realizado por el legislador en el año 1981 para equilibrar la norma legal, tan arcaica, a la realidad familiar española, definiendo incluso vías de evolución que apuntan a objetivos de equiparación con los países europeos; todo esto sin olvidar que aún subsisten restos del modelo familiar anterior, no sólo en la letra de la ley. sino en las conciencias y en la vida cotidiana de buena parte de la población.

Las contradicciones entre la generalidad, a nivel legislativo, del modelo igualitario-liberal - secular de familia y los rastros de tradicionalismo nos hacen volver a una explicación ya usada anteriormente, ${ }^{34}$ la de que coexisten en nuestro país dos modelos familiares divergentes, el moderno y el tradicional, que tienden, uno, a imponerse, y el otro a persistir en una tensión de fuerzas que da como resultado una enorme variedad de conductas familiares $\mathrm{y}$, sobre todo al estar ambos modelos bastante ligados a grupos de edad, un enorme conflicto generacional que divide a las familias de una forma más aguda quizá de lo que ha ocurrido en la evolución más lenta y continuada de los modelos familiares en la mayoría de los países europeos. $Y$ que esto ocurra así puede encontrar su explicación en la historia política reciente por la pervivencia durante muchos años de una imposición de formas familiares demasiado rígidas y arcaicas, impidiendo una evolución más paulatina, de manera que, y esto se ve muy claramente en los cambios legislativos que son muy bruscos, se ha pasado de modelos absolutamente

34. 1. Alberdi. 
tradicionales de ideas y comportamientos a otros muy diferentes y nuevos. Políticamente se ha impedido la transición familiar cuando ésta estaba ocurriendo en Europa, y al postergarse ha ocurrido de forma muy rápida, agudizando los conflictos que necesariamente produce.

Pues no podemos olvidar que, aunque hemos tratado de analizar un modelo de familia en su vigencia o no en la configuración simbólica de la familia, nos hemos limitado a examinar el cambio legal textual, dejando para otro ocasión el contrastar hasta qué punto es válido o no hablar en los mismos términos de la realidad familiar actual. Una pregunta subsiste, esa tensión entre un modelo familiar tradicional y las nuevas formas de entender las relaciones entre esposos, entre parejas, entre padres e hijos que es innegable, ¿hacia cuál de las dos opciones se inclina? Las formas familiares nuevas, ¿responden numéricamente a la mayoría del país? $\mathrm{O}$, aun siendo el modelo simbólico dominante, ¿se reducen en su experiencia real a grupos todavía minoritarios? 